\title{
Follistatin-288-Fc Fusion Protein Promotes Localized Growth of Skeletal Muscle ${ }^{\text {[] }}$
}

\author{
Roselyne Castonguay, Jennifer Lachey, ${ }^{1}$ Samantha Wallner, ${ }^{2}$ Jamie Strand, ${ }^{3}$ Katia Liharska, \\ Abigail E. Watanabe, ${ }^{4}$ Marishka Cannell, Monique V. Davies, ${ }^{5}$ Dianne Sako, Megan E. Troy, \\ Lavanya Krishnan, Aaron W. Mulivor, ${ }^{6}$ Huiming Li, Sarah Keates, Mark J. Alexander, \\ R. Scott Pearsall, and Ravi Kumar
}

Acceleron Pharma, Cambridge, Massachusetts

Received July 30, 2018; accepted December 6, 2018

\section{ABSTRACT}

Follistatin is an endogenous glycoprotein that promotes growth and repair of skeletal muscle by sequestering inhibitory ligands of the transforming growth factor- $\beta$ superfamily and may therefore have therapeutic potential for neuromuscular diseases. Here, we sought to determine the suitability of a newly engineered follistatin fusion protein (FST288-Fc) to promote localized, rather than systemic, growth of skeletal muscle by capitalizing on the intrinsic heparin-binding ability of the follistatin-288 isoform. As determined by surface plasmon resonance and cell-based assays, FST288-Fc binds to activin $A$, activin B, myostatin (growth differentiation factor GDF8), and GDF11 with high affinity and neutralizes their activity in vitro. Intramuscular administration of FST288-Fc in mice induced robust, dose-dependent growth of the targeted muscle but not of surrounding or contralateral muscles, in contrast to the systemic effects of a locally administered fusion protein incorporating activin receptor type IIB (ActRIIB-Fc). Furthermore, systemic administration of FST288-Fc in mice did not alter muscle mass or body composition as determined by NMR, which again contrasts with the pronounced systemic activity of ActRIIB-Fc when administered by the same route. Subsequent analysis revealed that FST288-Fc in the circulation undergoes rapid proteolysis, thereby restricting its activity to individual muscles targeted by intramuscular administration. These results indicate that FST288-Fc can produce localized growth of skeletal muscle in a targeted manner with reduced potential for undesirable systemic effects. Thus, FST288-Fc and similar agents may be beneficial in the treatment of disorders with muscle atrophy that is focal, asymmetric, or otherwise heterogeneous.

\section{Introduction}

Disease-dependent myopathies can produce focal weakness in skeletal muscle, including deficits that are asymmetric or differentially impact individual muscles or muscle groups (Terry et al., 2018). Among disorders with such deficits are many rare and debilitating neuromuscular diseases with no known cure and limited treatment options. One of the most common examples is facioscapulohumeral muscular dystrophy, an autosomal dominant disease with muscle-based etiology that presents clinically with progressive weakening of the facial, scapular, and humeral muscles (Stübgen and Stipp, 2010). Other disorders with localized muscle deficits are fundamentally neuropathic, such as CharcotMarie-Tooth disease, in which case patients experience muscle

\footnotetext{
${ }^{1}$ Current affiliation: Keros Therapeutics, Lexington, MA.

${ }^{2}$ Current affiliation: NovaRock Biotherapeutics, Princeton, NJ.

${ }^{3}$ Current affiliation: Surface Oncology, Cambridge, MA.

${ }^{4}$ Current affiliation: Selecta Biosciences, Watertown, MA

${ }^{5}$ Current affiliation: now retired.

${ }^{6}$ Current affiliation: The Hospital for Sick Children, Toronto, Canada

https://doi.org/10.1124/jpet.118.252304.

S This article has supplemental material available at jpet.aspetjournals.org.
}

weakness and atrophy primarily in their limbs, with the longest axonal fibers and distal musculature most vulnerable to impairment at early stages of the disease (McCorquodale et al., 2016).

Transforming growth factor- $\beta$ (TGF- $\beta$ ) superfamily signaling pathways are important regulators of skeletal muscle growth and repair. The ligand myostatin (growth differentiation factor GDF8), encoded by $M S T N$, is a well established endogenous inhibitor of myogenesis (McPherron and Lee, 1997; Lee et al., 2010). In addition, activins A and B, encoded by $I N H B A$ and $I N H B B$, have emerged as endogenous inhibitors of muscle growth (Gilson et al., 2009) that may act synergistically with myostatin (Chen et al., 2017) and may be of particular importance in primates (Latres et al., 2017). GDF11, which is closely related to myostatin (Walker et al., 2017), has also been implicated as an inhibitor of muscle growth (Egerman et al., 2015; Hammers et al., 2017; Zimmers et al., 2017). These ligands exert their effects by triggering formation of heteromeric complexes between certain type I and type II receptors that activate the small mothers against decapentaplegic 2/3 (Smad2/3) pathway to regulate gene transcription (Schmierer and Hill, 2007).

ABBREVIATIONS: ActRIIB-Fc, activin receptor type IIB-Fc fusion protein; BMP, bone morphogenetic protein; BSA, bovine serum albumin; FSD, follistatin domain; FST288, follistatin-288 isoform; FST288-Fc, follistatin-288-lgG 1 Fc fusion protein; FST315, follistatin-315 isoform; GDF, growth differentiation factor; HBS, heparin-binding site; hFc, human Fc; PBS, phosphate-buffered saline; PVDF, polyvinylidene difluoride; SPR, surface plasmon resonance; TBS, Tris-buffered saline; TGF- $\beta$, transforming growth factor- $\beta$. 
Follistatins are widely expressed glycoproteins that act as extracellular ligand traps to regulate bioavailability of myostatin, activins, GDF11, and some bone morphogenetic proteins (BMPs) (Nakamura et al., 1990; Fainsod et al., 1997; Iemura et al., 1998; Schneyer et al., 2003, 2008; Amthor et al., 2004; Thompson et al., 2005; Cash et al., 2009; Walker et al., 2017). The follistatin gene (FST) generates two precursors by alternative splicing, either 344 or 317 residues in length, which are post-translationally modified to produce mainly isoforms of 315 residues (FST315) or 288 residues (FST288), respectively (Shimasaki et al., 1988) (Fig. 1). All follistatin isoforms contain an N-terminal domain and three follistatin domains (FSD1, FSD2, and FSD3), with a heparin-binding site (HBS) located in FSD1 that promotes binding to extracellular proteoglycans (Nakamura et al., 1991; Inouye et al., 1992; Innis and Hyvönen, 2003). FST315, which is considered the major circulating form (Schneyer et al., 2004), possesses an additional C-terminal domain containing an acidic region that may interact with basic residues in the HBS, thereby reducing the affinity of ligand-free FST315 for proteoglycans (Sugino et al., 1993; Lerch et al., 2007). Absence of the C-terminal domain from FST288 allows this isoform to bind avidly to proteoglycans and therefore function as a tethered form for inhibition of pericellular ligand signaling (Bilezikjian et al., 2004; Sidis et al., 2006). Mutual interactions between follistatin-proteoglycan binding and follistatin-ligand binding are thought to influence ligand clearance and bioavailability, as best understood in the case of FST288 and activin A (Sumitomo et al., 1995; Hashimoto et al., 1997; Sidis et al., 2005; Lerch et al., 2007; Cash et al., 2009; Zhang et al., 2012).

Follistatin-based interventions have shown the potential to promote muscle hypertrophy and improve muscle function. For example, transgenic mice overexpressing FST288 specifically in skeletal muscle exhibit greater muscle growth than do mice deficient in myostatin alone (Lee and McPherron, 2001; Lee, 2007). Virally mediated transfer of FST288 or FST315 genes induces muscle growth in mice (Haidet et al., 2008; Winbanks et al., 2012) and nonhuman primates (Kota et al., 2009). In addition, an engineered FST315 fusion protein with deleted HBS promoted muscle growth and repair after systemic administration in mouse models of muscle injury (Datta-Mannan et al., 2013; Yaden et al., 2014). Together, these studies support the concept of follistatin-based agents for systemic muscle therapy, but do not directly address the potential use of such agents for targeted local therapy.

The objective of this study was to determine the suitabil-

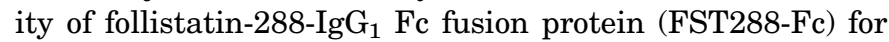
promoting targeted growth of skeletal muscle. Here, we characterize this follistatin fusion protein with regard to its ligand-binding properties, activity in vitro, and effectiveness in vivo. In addition, we examine its proteolytic degradation and highlight properties that would potentially make this protein a useful locally acting muscle agent.

\section{Materials and Methods}

Construction, Expression, and Purification of Recombinant FST288-Fc. A nucleotide sequence encoding the human FST317 precursor (National Center for Biotechnology Information reference sequence NP_006341.1) was cloned upstream and in frame with a sequence encoding the human IgG1 Fc domain in the vector ubiquitous chromatin opening element pAID4T.hFc. This vector contains a ubiquitous chromatin opening element (Millipore, Burlington, MA) for increased gene expression. The plasmid was stably transfected in Chinese hamster ovary DUKX cells, and a pool was generated and used to express the fusion protein FST288-Fc. The protein was purified following a three-step procedure. First, the protein was captured on a protein A MabSelect Sure chromatography column (GE Healthcare, Boston, MA), then washed and eluted with glycine at low $\mathrm{pH}$. Fractions from the elution were neutralized and pooled before being loaded over a hydroxyapatite column (CHT Ceramic Hydroxyapatite Type II; Bio-Rad, Hercules, CA) and eluted with a gradient of sodium phosphate at $\mathrm{pH}$ 7. This material was then used on a polishing size-exclusion chromatography column (GE Healthcare) to remove any remaining aggregates. The final material was dialyzed in phosphate-buffered saline (PBS), and purity was assessed by SDS-PAGE gel with SimplyBlue SafeStain (Life Technologies, Carlsbad, CA) and an analytical size-exclusion chromatography column (TSK G3000SWXL; Tosoh, King of Prussia, PA) to be greater than $95 \%$ pure.

FST288-Fc Protein Sequence. The FST288-Fc protein sequence was as follows: GNCWLRQAKNGRCQVLYKTELSKEECCSTGRLST SWTEEDVNDNTLFKWMIFNGGAPNCIPCKETCENVDCGPGKKC RMNKKNKPRCVCAPDCSNITWKGPVCGLDGKTYRNECALLKAR CKEQPELEVQYQGRCKKTCRDVFCPGSSTCVVDQTNNAYCVTC NRICPEPASSEQYLCGNDGVTYSSACHLRKATCLLGRSIGLAYEG KCIKAKSCEDIQCTGGKKCLWDFKVGRGRCSLCDELCPDSKSDE PVCASDNATYASECAMKEAACSSGVLLEVKHSGSCNTGGGTHT CPPCPAPELLGGPSVFLFPPKPKDTLMISRTPEVTCVVVDVSHED PEVKFNWYVDGVEVHNAKTKPREEQYNSTYRVVSVLTVLHQDW LNGKEYKCKVSNKALPAPIEKTISKAKGQPREPQVYTLPPSREE MTKNQVSLTCLVKGFYPSDIAVEWESNGQPENNYKTTPPVLDS DGSFFLYSKLTVDKSRWQQGNVFSCSVMHEALHNHYTQKSLSL SPGK.

Evaluation of Ligand Binding to FST288-Fc by Surface Plasmon Resonance. Ligand binding to FST288-Fc was characterized by surface plasmon resonance (SPR) using a Biacore T100 instrument (GE Healthcare), and kinetic assays were performed in a capture format. Proteins were generated internally unless otherwise indicated. Goat anti-human Fc-specific IgG (Thermo Fisher Scientific, Waltham, MA) was immobilized onto a research-grade CM5 chip using standard amine coupling chemistry following the manufacturer's protocol. FST288-Fc was captured on the experimental flow cell, while another flow cell was used as a reference (control) to subtract for nonspecific binding, drift, and bulk refractive index. The FST288Fc/antibody complex was stable over the time course of each ligandbinding cycle. A concentration series of activin A, activin B, GDF8, or GDF11 (0.039-20 nM, with 2-fold serial dilutions) was injected over experimental and control flow cells at a flow rate of $100 \mu \mathrm{l} / \mathrm{min}$ at $37^{\circ} \mathrm{C}$. The antibody surface was regenerated between binding cycles by injection of $10 \mathrm{mM}$ glycine, $\mathrm{pH}$ 1.7. Running buffer contained $0.01 \mathrm{M}$ HEPES ( $\mathrm{pH} 7.4$ ), $0.5 \mathrm{M} \mathrm{NaCl}, 3 \mathrm{mM}$ EDTA, 0.005\% (v/v) surfactant $\mathrm{P} 20$, and $0.5 \mathrm{mg} / \mathrm{ml}$ bovine serum albumin (BSA). All sensorgrams were processed by double referencing (subtraction of the responses from the reference surface and from an average of blank buffer injections). To obtain kinetic rate constants, BIAevaluation software (GE Healthcare) was used to fit the corrected data to a 1:1 interaction model that includes a term for mass transport. The equilibrium dissociation constant $K_{\mathrm{D}}$ was determined by the ratio of binding rate constants $k_{\mathrm{d}} / k_{\mathrm{a}}$.

Luciferase Reporter-Gene Assay in A204 Cells. A reportergene assay was used to evaluate the effects of FST288-Fc on signaling by TGF- $\beta$ superfamily ligands. This assay is based on the human rhabdomyosarcoma cell line A204 cotransfected with a pGL3 CAGA12-luciferase reporter plasmid (Korchynskyi and ten Dijke, 2002; David et al., 2007) and a Renilla reporter plasmid (pRLCMVluciferase) to control for transfection efficiency. The CAGA12 motif is present in the TGF- $\beta$-responsive gene (plasminogen activator inhibitor-1), so this vector is of general use for factors signaling through Smad2/3 (Korchynskyi and ten Dijke, 2002; David et al., 2007). A204 
A Follistatin isoforms

FST288 precursor (317 aa)

HBS

\begin{tabular}{|l|l|l|l|l|}
\hline SP & ND & FSD1 & FSD2 & FSD3 \\
\hline
\end{tabular}

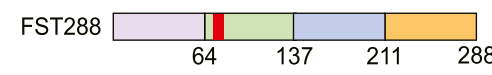

B FST288-Fc fusion protein HBS
FST315 precursor (344 aa)

HBS

\begin{tabular}{|l|l|l|l|l|l|}
\hline SP & ND & FSD1 & FSD2 & FSD3 & CD \\
\hline
\end{tabular}

\begin{tabular}{|c|c|c|c|c|}
\hline \multirow[t]{2}{*}{ FST315 } & 1 & & & \\
\hline & 64 & 137 & 211 & 288315 \\
\hline ST30 & 1 & & & \\
\hline & 64 & 137 & 211 & 303 \\
\hline
\end{tabular}

Fig. 1. Primary structure of native follistatin isoforms and engineered follistatin-288-Fc fusion protein. (A) Follistatin isoforms FST315, FST303, and FST288 are generated from a single gene by alternative splicing and post-translational modification. (B) FST288-Fc fusion protein consists of the native FST288 sequence (including its HBS) attached to human IgG1 Fc, which facilitates dimerization. aa, amino acid; CD, C-terminal domain; ND, N-terminal domain; SP, signal peptide.

\begin{tabular}{|l|l|l|l|l|}
\hline ND & FSD1 & FSD2 & FSD3 & FC \\
\hline
\end{tabular}

cells (HTB-82; ATCC, Manassas, VA) were distributed in 48-well plates at $10^{5}$ cells per well in McCoy's 5A growth medium (Thermo Fisher Scientific) supplemented with $10 \%$ fetal bovine serum and incubated overnight at $37^{\circ} \mathrm{C}$ with $5 \% \mathrm{CO}_{2}$. The next day, a solution containing $10 \mu \mathrm{g}$ pGL3 CAGA12-luciferase, $0.1 \mu \mathrm{g}$ pRLCMV-luciferase, $30 \mu \mathrm{l}$ XtremeGene 9 (Roche Diagnostics, Indianapolis, IN), and $970 \mu \mathrm{l}$ OptiMEM (Invitrogen, Carlsbad, CA) was preincubated for 30 minutes at room temperature before it was added to $24 \mathrm{ml}$ assay buffer (McCoy's 5A medium supplemented with $0.1 \%$ BSA). This mixture was applied to the plated cells $(500 \mu \mathrm{l} /$ well $)$. After an overnight transfection, the medium was removed and replaced with activin $\mathrm{A}$, activin B, or GDF11 (each $5 \mathrm{ng} / \mathrm{ml}$ ) or GDF8 (45 ng/ml) plus serially diluted FST288-Fc $(250 \mu \mathrm{l})$. The 3-fold dilutions of FST288-Fc produced a final concentration range of $0.46-1000 \mathrm{ng} / \mathrm{ml}$ for testing with activin A, GDF8, and GDF11 and $0.16-350 \mathrm{ng} / \mathrm{ml}$ for activin B. After a 6-hour incubation with test ligands and inhibitor, the cells were lysed. Reporter activity was measured using a dual luciferase reporter assay system (Promega, Madison, WI) according to the manufacturer's instructions. The luciferase activity of the experimental reporter was normalized to the activity of the Renilla control. The $\mathrm{IC}_{50}$ values were calculated using GraphPad Prism software (GraphPad Software Inc., La Jolla, CA).

Animal Care. Original studies in animals were carried out in accordance with the Guide for the Care and Use of Laboratory Animals, as adopted and promulgated by the U.S. National Institutes of Health, and were approved by the Acceleron Pharma Institutional Animal Care and Use Committee.

Administration of FST288-Fc and Activin Receptor Type IIB-Fc Fusion Protein in Mice. Eight-week-old male C57BL/ 6 NTac mice were obtained from Taconic (Germantown, NY) and allowed to acclimate to the animal facility for 7 days. At the end of the acclimation period, mice were treated by intramuscular or subcutaneous injection twice weekly for 4 weeks with FST288-Fc, activin receptor type IIB-Fc fusion protein (ActRIIB-Fc) generated internally as in Cadena et al. (2010), or vehicle consisting of Tris-buffered saline (TBS). Animal weights were monitored twice weekly throughout the study, and body composition was analyzed by NMR (Minispec; Bruker, Billerica, MA) on day 0 and at the end of study on day 28. At the completion of the treatment period, mice were euthanized by $\mathrm{CO}_{2}$ asphyxiation and individual muscle groups were removed and weighed.

Stability of Intact FST288-Fc in Serum and Muscle. C57BL/6 mice were given intraperitoneal injections of FST288-Fc $(10 \mathrm{mg} / \mathrm{kg})$ at time zero. Mice were euthanized at 0, 0.5, 2, 6, 10, 24, 32, 48, 72, and 96 hours postinjection ( $n=5$ per time point), at which time serum was collected and frozen at $-80^{\circ} \mathrm{C}$ and both gastrocnemius muscles were collected and flash-frozen in liquid nitrogen. A similar experiment was performed with FST288-Fc administered intramuscularly $(10 \mathrm{mg} / \mathrm{kg})$ in the gastrocnemius. To prepare muscle lysates, the frozen muscles were diced and incubated in $1 \mathrm{ml}$ cold radioimmunoprecipitation assay buffer supplemented with protease inhibitors (1:100) for 10 minutes. Muscles were then homogenized using a Dremel Tissue Tearor (Biospec, Bartlesville, OK) and centrifuged to remove any unwanted tissue fragments. Stability of intact FST288-Fc in serum and muscle samples was evaluated by Western blotting. Serum samples were diluted 1:20 prior to SDSPAGE analysis, and muscle lysate samples were normalized to $18 \mu \mathrm{g}$ total protein per well. Total protein in muscle lysates was measured using an RC DC Protein Assay Kit II (Bio-Rad). Proteins were transferred to a polyvinylidene difluoride (PVDF) membrane, and intact FST288-Fc and major fragments were detected by Western blotting with a polyclonal human/mouse anti-follistatin biotinylated antibody (R\&D Systems, Minneapolis, MN) at a 1:1000 dilution (as a primary antibody) and horseradish peroxidase-avidin (Vector Laboratories, Burlingame, CA) at a 1:10,000 dilution (as a secondary antibody). All dilutions were done in TBS (pH 8.0) plus $0.1 \%$ Tween 20. Bands were detected with SuperSignal West Pico Chemiluminescent Substrate (Thermo Fisher Scientific). Using Bio-Rad Image Laboratory 5.0 software, relative levels of FST288-Fc were calculated by comparing with the internal control FST288-Fc (5 ng) present on each Western blot.

The polyclonal anti-FST antibody used in this study was carefully chosen from among multiple candidates based on extensive testing and taking into account competing factors. We originally sought an antibody that would detect FST polypeptides by Western blot under both reduced and nonreduced conditions but could not find one. We then tested four commercially available antibodies (including one monoclonal) to determine which yielded optimal FST detection in serum and muscle. In our testing, we made sure to include biotinylated antibodies to benefit from their better signal-to-noise ratio. Despite yielding some nonspecific bands, the biotinylated polyclonal antibody eventually used for this study was the best of the candidates tested and produced readily interpretable results.

SPR Analysis of FST288-Fc Cleavage Products in the Mouse Circulation. Serum from mice treated systemically with FST288-Fc was analyzed by SPR with a Biacore T100 instrument (GE Healthcare) to determine whether circulating FST288 cleavage products containing a human $\mathrm{Fc}(\mathrm{hFc})$ domain are able to bind activin $\mathrm{A}$ as a proxy for ligand binding generally. A standard curve was generated by spiking FST288-Fc into mouse serum to produce final concentrations of $0,62.5,125,250$, and $500 \mathrm{ng} / \mathrm{ml}$. Serum samples taken from mice treated with FST288-Fc for $0,10,24,32$, and 48 hours were diluted 10-fold in Biacore buffer [10 mM HEPES, pH 7.4, $500 \mathrm{mM}$ $\mathrm{NaCl}, 3 \mathrm{mM}$ EDTA, $0.005 \%$ (v/v) surfactant P20, and $0.5 \mathrm{mg} / \mathrm{ml} \mathrm{BSA]}$ for ligand capture. Activin A was prepared in the same buffer at $10 \mathrm{nM}$. Standards and serum samples were captured at a flow rate of $10 \mu \mathrm{l} / \mathrm{min}$ for 45 seconds by a CM5 sensorchip (GE Healthcare) on which approximately $5000 \mathrm{RU}$ of anti-human Fc-specific IgG (Millipore Sigma) was immobilized for each flow cell. Activin A was then injected at $70 \mu \mathrm{l} / \mathrm{min}$ for 200 seconds. The amount of hFc protein captured was obtained from the "Capture" tab in Biacore T200 Evaluation Software (version 3.1; GE Healthcare), and the amount of activin A bound was recorded as a report point 10 seconds after the end of activin $\mathrm{A}$ injection. 
Immunoprecipitation of FST288-Fc Cleavage Products in Serum. Male mice were injected intraperitoneally with $10 \mathrm{mg} / \mathrm{kg}$ FST288-Fc, and serum was collected after 24 hours. Streptavidin beads ( $3.2 \mathrm{ml}$ final volume after three washes in PBS) were then bound to approximately $400 \mu \mathrm{g}$ biotinylated polyclonal anti-follistatin antibody (R\&D Systems) by incubating them together in $2 \mathrm{ml}$ TBS with $0.1 \% \mathrm{BSA}$ at room temperature for 30 minutes. Beads were washed with PBS and then eluted five times with $3.2 \mathrm{ml} 0.1 \%$ trifluoroacetic acid in water to remove any loosely bound antibody. Next the resin was washed with PBS and then incubated with the collected mouse serum samples (precleared by incubating with $3.2 \mathrm{ml}$ unbound streptavidinagarose beads) at room temperature for 1 hour. After washes with PBS and PBS plus $0.05 \%$ P-20 (GE Healthcare), an elution was performed with 3.2-ml fractions of $0.1 \%$ trifluoroacetic acid in water until no more elution of protein was observed by SDS-PAGE gel stained with silver stain. The fractions were then concentrated using Ultra MicroSpin C4 columns (GE Healthcare) and a CentriVap Benchtop Vacuum Concentrator (Labconco, Kansas City, MO) was used to concentrate samples before they were loaded onto a SDS-PAGE gel.

N-Terminal Sequencing of Immunoprecipitated FST288-Fc Cleavage Products. Immunoprecipitated proteins were reduced with $\beta$-mercaptoethanol and transferred onto a Sequi-Blot PVDF membrane (Bio-Rad). After protein transfer, the membrane was stained briefly (approximately 2 minutes) with GelCode Blue Stain (Thermo Fisher Scientific), and the background stain was removed with three washes of $50 \%(\mathrm{v} / \mathrm{v})$ methanol. The stained membrane was rinsed with $10 \%$ methanol and dried. PVDF-bound protein bands were excised and subjected to Edman chemical sequencing performed on a Procise Protein Sequencing System (Applied Biosystems, Foster City, CA) equipped with an Applied Biosystems model 491-0 gasphase Procise protein sequencer, an ABI 140C high-performance liquid chromatography pump, and a variable wavelength UV detector. Sequence data were analyzed using Sequence Pro software. All reagents and solvents used for the sequencer were obtained from Life Technologies (Applied Biosystems). The derivatized phenylthiohydantoin amino acid standards solution was diluted in acetonitrile plus $\mathrm{N}$-acetylcysteine (reagent R5B) four times to provide a $10 \mathrm{pmol}$ load on the Procise sequencer and was used before analyzing each sample. The standard sequencing pulse-liquid PVDF method was applied for sequencing over the course of 10 cycles.

Mass Spectrometric Analysis of Immunoprecipitated FST288-Fc Cleavage Products. Proteins recovered from serum by immunoprecipitation with anti-follistatin antibody were analyzed by mass spectroscopy. They were first deglycosylated with PNGase F (New England Biolabs, Ipswich, MA) and sialidase A (ProZyme, Hayward, $\mathrm{CA}$ ), then reduced and alkylated with iodoacetamide. Samples were then injected directly in line (no UV detector) on an Xbridge C4 reversed phase liquid chromatography column (Waters Corporation, Milford, MA), and the elution was monitored on a LTQ Orbitrap XL mass spectrometer (Thermo Fisher Scientific). Average ions were deconvoluted using Promass software (Thermo Fisher Scientific).

Statistical Analysis. Data were analyzed by the unpaired $t$ test for between-group comparisons and are reported as means \pm S.E.M. unless indicated otherwise.

\section{Results}

Ligand Neutralizing Activity of FST288-Fc In Vitro. We generated a dimeric Fc fusion protein based on the native FST288 isoform by fusing human FST288 to a human IgG1 Fc domain (Fig. 1B). This was done to confer several advantages, including simplified purification as well as extended pericellular half-life due to higher molecular weight, delayed lysosomal degradation arising from its binding to neonatal $\mathrm{Fc}$ receptor (Rath et al., 2015), and a doubling of HBS as a consequence of dimerization.
TABLE 1

Ligand-binding parameters and inhibitory activity for FST288-Fc as determined by SPR and cell-based reporter-gene assay

\begin{tabular}{lcccc}
\hline \multirow{2}{*}{ Ligand } & \multicolumn{3}{c}{ SPR } & $\begin{array}{c}\text { Reporter-Gene } \\
\text { Assay, IC }\end{array}$ \\
\cline { 2 - 4 } & $k_{\mathrm{a}}$ & $k_{\mathrm{d}}$ & $K_{\mathrm{D}}$ & \\
\hline & $M^{-1} s^{-1}$ & $s^{-1}$ & $p M$ & $p M$ \\
Activin A & $1.14 \times 10^{6}$ & $2.24 \times 10^{-4}$ & 196 & 70.3 \\
Activin B & $1.52 \times 10^{7}$ & $7.45 \times 10^{-5}$ & 4.91 & 88.9 \\
GDF8 & $9.48 \times 10^{5}$ & $5.52 \times 10^{-5}$ & 58.3 & 2070 \\
GDF11 & $2.11 \times 10^{6}$ & $9.41 \times 10^{-5}$ & 44.6 & 217 \\
\hline
\end{tabular}

Kinetic characterization of ligand binding to FST288-Fc was assessed by SPR Data were globally fit to a 1:1 binding model with the mass transfer term using BIAevaluation software. The inhibitory activity of FST288-Fc was measured in dual luciferase reporter assays carried out in A204 cells. The $\mathrm{IC}_{50}$ for each curve was calculated using XLfit ( $n=3$ replicates on the same plate).

SPR was used to characterize binding of FST288-Fc to the well established FST ligands activin A, activin B, myostatin (GDF8), and GDF11. The apparent equilibrium dissociation constants $\left(K_{\mathrm{D}}\right)$ ranged from approximately 5 to $200 \mathrm{pM}$, and the dissociation rate constants $\left(k_{\mathrm{d}}\right)$ ranged from approximately $2 \times 10^{-4}$ to $5 \times 10^{-5} \mathrm{~s}^{-1}$ (Table 1 ). We also evaluated whether FST288-Fc interacts with the vascular regulatory ligand BMP9 (David et al., 2008) but did not observe appreciable binding (data not shown). These data confirm that FST288-Fc binds tightly to several ligands involved in the negative regulation of skeletal muscle mass. The slow rate of dissociation of these ligands from FST288-Fc further establishes the fusion protein's effectiveness as a ligand trap under cell-free conditions.

We then used a reporter-gene assay to determine whether FST288-Fc is able to neutralize signaling by these key ligands through their cognate receptors in a cell-based system. FST288-Fc inhibited signaling by activin A, activin B, GDF8, and GDF11 in a dose-dependent manner with $\mathrm{IC}_{50}$ values in the range of picomoles to low nanomoles (Table 1). These data demonstrate that FST288-Fc potently inhibits signaling by these ligands in a cell-based system in vitro.

Local Administration of FST288-Fc Causes Focal Growth of Skeletal Muscle in Mice. We conducted a series of experiments in wild-type mice to determine whether intramuscular administration of FST288-Fc exerts effects on the targeted muscle and potentially on skeletal muscles more broadly. Unilateral intramuscular administration of FST288-Fc in the gastrocnemius muscle (right side) twice weekly for 4 weeks increased the weight of the injected muscle by $38 \%$ compared with vehicle while having no detectable effect on the contralateral, uninjected gastrocnemius (Fig. 2A). By comparison, unilateral intramuscular administration of ActRIIB-Fc, an agent with a well demonstrated ability to produce systemic muscle hypertrophy (Cadena et al., 2010), increased muscle weight in both the injected and uninjected gastrocnemius muscles by approximately $52 \%$ and $38 \%$, respectively (Fig. 2A). Thus, local administration of FST288-Fc induces muscle growth ipsilaterally but not contralaterally, whereas local administration of ActRIIB-Fc induces muscle growth both ipsilaterally and contralaterally.

We next assessed whether local administration of FST288-Fc produces systemic changes in body composition in mice by comparing its effects with those of locally administered ActRIIB-Fc. Ligands in the TGF- $\beta$ superfamily are implicated in the regulation of adipose tissue mass as well as 
A

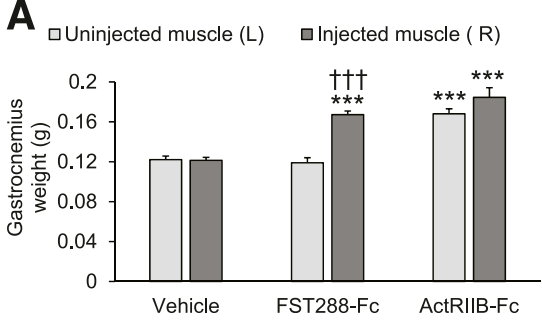

C

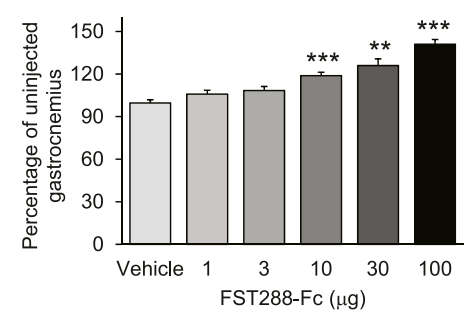

E

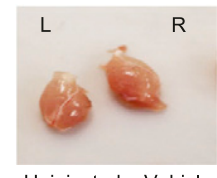

Uninjected Vehicle
B

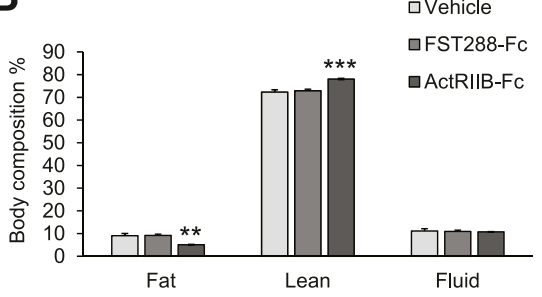

D
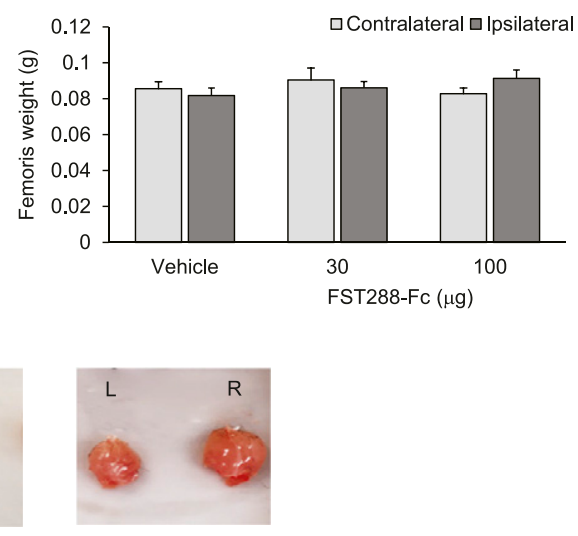

Uninjected FST288-Fc
Fig. 2. Local administration of FST288-Fc in mice causes dose-dependent growth of targeted skeletal muscle without widespread muscle effects. Mice were treated by unilateral injection in the gastrocnemius muscle ( $\mathrm{R}$, right side) twice weekly for 4 weeks. (A) Weights of FST288-Fc-injected, ActRIIB-Fc-injected, vehicle-injected, and uninjected (contralateral) gastrocnemius muscles. Data are means \pm S.E.M. $(n=5)$. *** $P \leq 0.001$ vs. vehicle by unpaired $t$ test; ${ }^{\dagger \dagger} P \leq$ 0.001 vs. uninjected gastrocnemius muscle by unpaired $t$ test. (B) Whole-body composition expressed as percentages of fat, lean tissue, and fluid, determined by NMR scan of mice injected unilaterally in the gastrocnemius muscle with FST288-Fc $(100 \mu \mathrm{g})$, ActRIIB-Fc $(100 \mu \mathrm{g})$, or vehicle (TBS). Data are means \pm S.E.M. $(n=5)$. $* * P \leq 0.01 ; * * * P \leq 0.001$ vs. vehicle by unpaired $t$ test. (C) Dose-dependent increase in weight of injected gastrocnemius muscle in mice treated with FST288-Fc or vehicle (TBS). Data are expressed as the ratio of injected muscle weight to weight of the uninjected gastrocnemius. Data are means \pm S.E.M. $(n=5) . * * P \leq 0.01 ; * * * P \leq 0.001$ vs. vehicle by unpaired $t$ test. (D) Weights of femoris muscles either adjacent (ipsilateral) or contralateral to the injected gastrocnemius muscles from mice in (C) treated with vehicle or the two highest doses of FST288-Fc. Data are means \pm S.E.M. $(n=5)$. (E) Representative images of injected gastrocnemius muscles (R) and their contralateral counterpart (L) excised from mice injected unilaterally with FST288-Fc $(100 \mu \mathrm{g})$ or vehicle (TBS). muscle mass, as demonstrated by effects of ActRIIB-Fc administration or follistatin overexpression (Koncarevic et al., 2012; Zheng et al., 2017). Compared with vehicle, unilateral intramuscular administration of FST288-Fc in the gastrocnemius twice weekly for 4 weeks did not alter total lean mass or total fat mass as determined by NMR (Fig. 2B). In contrast, unilateral intramuscular administration of ActRIIB-Fc in the gastrocnemius changed both total lean mass (8\% increase) and total fat mass (44\% decrease) (Fig. 2B). Neither agent altered total fluid volume. These results indicate that locally administered FST288-Fc does not produce systemic changes in muscle mass or fat mass, unlike locally administered ActRIIB-Fc.

We then investigated the dose-response relationship of local FST288-Fc administration to muscle growth. Unilateral intramuscular administration of FST288-Fc in the gastrocnemius at doses ranging from 1 to $100 \mu \mathrm{g}$ twice weekly for 4 weeks increased the weight of the injected muscle in a dose-dependent manner, resulting in increases of approximately $19 \%, 26 \%$, and $42 \%$ (compared with vehicle) at doses of 10,30 , and $100 \mu \mathrm{g}$, respectively (Fig. 2C). There was no evidence of this effect saturating within the dose range tested.

To further define the spatial extent of FST288-Fc activity after local administration, we examined potential effects of high doses on an untargeted muscle located close to the site of FST288-Fc injection. Unilateral intramuscular administration of FST288-Fc in the gastrocnemius twice weekly for 4 weeks did not alter the weight of either the ipsilateral or contralateral rectus femoris muscles (Fig. 2D). These results indicate that FST288-Fc at high doses does not cause an appreciable weight change even in a muscle adjacent to the injection site. Figure $2 \mathrm{E}$ shows representative images of gastrocnemius muscles from mice treated unilaterally with vehicle or FST288-Fc to illustrate the effectiveness of locally administered FST288-Fc in a targeted muscle.

Systemic Administration of FST288-Fc in Mice Does Not Alter Muscle Mass or Body Composition. Having demonstrated focal muscle growth after local administration of FST288-Fc, we sought to determine in mice whether FST288-Fc also causes muscle growth when administered systemically. Compared with vehicle, subcutaneous administration of FST288-Fc twice weekly for 4 weeks did not significantly affect total lean mass or total fat mass as determined by NMR (Fig. 3A). In contrast, administration of ActRIIB-Fc with the same dosing regimen increased total lean mass (by $8 \%$ ) and reduced total fat mass (by 47\%) compared with vehicle (Fig. 3A). Neither agent altered total fluid volume. The differential effects of these two agents on body composition after systemic administration closely resembles their effects on body composition when they are administered locally (Fig. 2B). Evaluation of individual muscles confirmed that systemic administration of FST288-Fc had no appreciable effect on weights of the pectoralis, tibialis anterior, gastrocnemius, or rectus femoris muscles, whereas systemic administration of ActRIIB-Fc increased weights of all four muscles by amounts ranging from $38 \%$ to $60 \%$ compared with vehicle (Fig. 3B). Together, these results indicate that systemic administration of FST288-Fc has little or no effect on muscle growth or body composition in mice even though ActRIIB-Fc at a comparable dose is biologically active.

FST288-Fc in the Circulation Is Rapidly Degraded to Fragments That Do Not Bind Ligand. To better understand the dependence of FST288-Fc activity on its route of administration, we next examined levels of intact FST288-Fc protein in muscle and serum after either local or systemic administration in mice. Representative blots used for analysis are depicted in Fig. 4, A, B, and D. Amounts of intact 
A

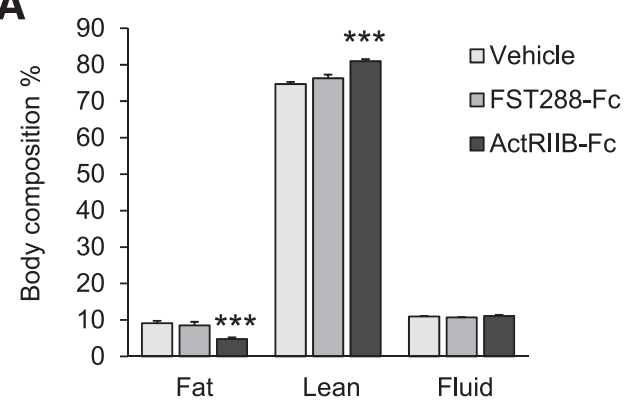

B

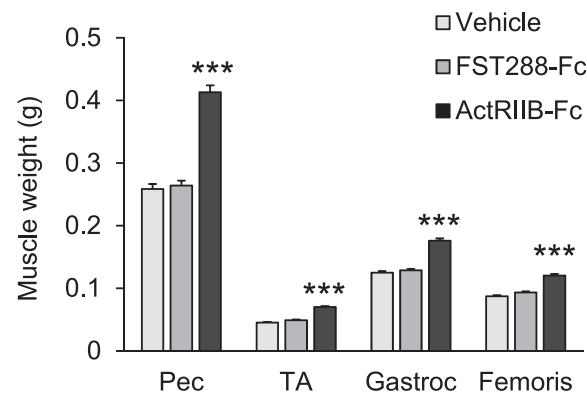

Fig. 3. Unlike ActRIIB-Fc, FST288-Fc causes no detectable muscle growth in mice when administered systemically. (A) Whole-body composition expressed as percentages of fat, lean tissue, and fluid, determined by NMR scan of mice treated subcutaneously with FST288-Fc $(10 \mathrm{mg} / \mathrm{kg})$, ActRIIB-Fc (10 mg/kg), or vehicle (TBS) twice weekly for 4 weeks. Data are means \pm S.E.M. $(n=10)$. $* * * P \leq 0.001$ vs. vehicle by unpaired $t$ test. (B) Weights of pectoralis (pec), tibialis anterior (TA), gastrocnemius (gastroc), and femoris muscles from mice treated subcutaneously with FST288-Fc (10 mg/kg), ActRIIB-Fc (10 mg/kg), or vehicle (TBS) twice weekly for 4 weeks. Data are means \pm S.E.M. $(n=10)$. $* * * P \leq 0.001$ vs. vehicle by unpaired $t$ test.

FST288-Fc in serum and muscle tissue were computed semiquantitatively by normalizing sample bands to the internal control present on each blot and were used to generate profiles of intact FST288-Fc levels over time in serum and muscle for each route of administration (Fig. $4, \mathrm{C}$ and $\mathrm{E}$ ).

This analysis revealed several differences in the distribution and availability of FST288-Fc associated with its route of administration. One difference was the magnitude and duration of muscle exposure to FST288-Fc. Intramuscular administration of FST288-Fc produced substantial levels of intact FST288-Fc protein in the targeted gastrocnemius muscle over the first 24 hours with continued presence of the intact protein evident up to 48 hours after injection (Fig. 4, B and C), with some FST288-Fc degradation products also apparent in the muscle at these time points. In contrast, systemic administration of FST288-Fc produced very low levels of intact FST288-Fc in muscle that became undetectable beyond 10 hours (Fig. 4E). Importantly, degradation of intact FST288-Fc was more rapid in the circulation than in muscle tissue (compare Fig. 4, C and E). After systemic administration, intact FST288-Fc reached maximum levels in serum by 0.5 hour and then declined to low levels by 24 hours (Fig. 4E). A cleavage product of FST288-Fc already present 0.5 hour after systemic administration became the predominant form in the circulation by 24 hours (Fig. 4D, 70-kDa band). These results indicate that circulating FST288-Fc is rapidly degraded by proteolytic cleavage.

To determine whether the cleavage products of FST288-Fc in the circulation still possess ligand-binding ability, we used
SPR to perform in vitro analysis of serum samples from mice treated systemically with FST288-Fc. First, serum samples collected at time points characterized by a high proportion of cleaved products $(10,24,32$, or 48 hours postadministration) were injected over an analytical chip coated with antibody against hFc (Supplemental Fig. 1A), thereby enabling binding and detection of intact FST288-Fc as well as any cleavage products containing the $\mathrm{hFc}$ domain. In a second step, the captured proteins in these samples were exposed to activin A to assess ligand binding at each time point (Supplemental Fig. 1B). Importantly, activin A binding as a fraction of captured hFc-containing proteins declined rapidly to negligible levels during this time interval, indicating degradation of intact FST288-Fc to nonbinding cleavage products. Together, the foregoing results identify accelerated degradation of FST288-Fc in the circulation and low bioavailability of the fusion protein in muscle tissue as major factors contributing to inactivity of FST288-Fc when administered systemically.

Characterization of FST288-Fc Cleavage Products in the Circulation. We next sought to better understand the loss of intact FST288-Fc fusion protein in the circulation. FST288-Fc was incubated in PBS, naïve human serum, or whole blood at $37^{\circ} \mathrm{C}$ for 3 days to detect signs of degradation; however, no evidence of proteolysis was obtained by Western blot (data not shown). We inferred from this negative result that the $70-\mathrm{kDa}$ cleavage product was the result of an active process occurring in vivo. As a next step, mice were treated with FST288-Fc (10 mg/kg, i.p.), and serum was collected at 24 hours post-treatment when the majority of FST288-Fc was no longer intact (Fig. 4C). Proteins in the serum samples were separated by SDS-PAGE under reducing and nonreducing conditions and the resulting blots were probed using an antibody against $\mathrm{hFc}$. Under nonreducing conditions, a $70-\mathrm{kDa}$ band was observed corresponding to that previously seen with an anti-follistatin antibody (Supplemental Fig. 2A). Under reducing conditions, however, two bands were detected. One band of approximately $35 \mathrm{kDa}$ appeared to correspond to an Fc monomer, while the other band of approximately $40 \mathrm{kDa}$ was hypothesized to correspond to monomeric Fc coupled to a truncated follistatin polypeptide (Supplemental Fig. 2B).

We characterized these FST288-Fc cleavage fragment(s) as an initial step toward engineering FST288 variants with altered ligand binding profiles and/or resistance to cleavage in vivo. FST288-Fc cleavage products in serum at 24 hours postadministration were analyzed as shown in Fig. 5A. Serum from mice injected systemically with FST288-Fc (10 mg/kg, i.p.) was subjected to immunoprecipitation with the polyclonal antifollistatin antibody used previously for Western blotting. Proteins recovered by immunoprecipitation were then reduced and separated by SDS-PAGE gel and transferred to PVDF membrane. Several bands of approximately $40 \mathrm{kDa}$ were excised and analyzed using an $\mathrm{N}$-terminal sequencer (Fig. 5B). A sequence starting with $\mathrm{AKS} * \mathrm{E}$ was detected, with the asterisk corresponding to a Cys in the follistatin sequence. In addition, immunoprecipitated proteins were reduced, deglycosylated, alkylated, and subjected to mass spectrometric analysis using $\mathrm{C} 4$ reversed phase liquid chromatography-mass spectrometry. The resulting total ion chromatogram shown in Fig. 5C contained a small peak at 31.72 minutes corresponding to follistatin sequences and was subsequently analyzed using Promass software. Two FST288-Fc protein fragments were identified in this peak, with masses of 34,421 and 35,301 Da (Fig. 5D). 

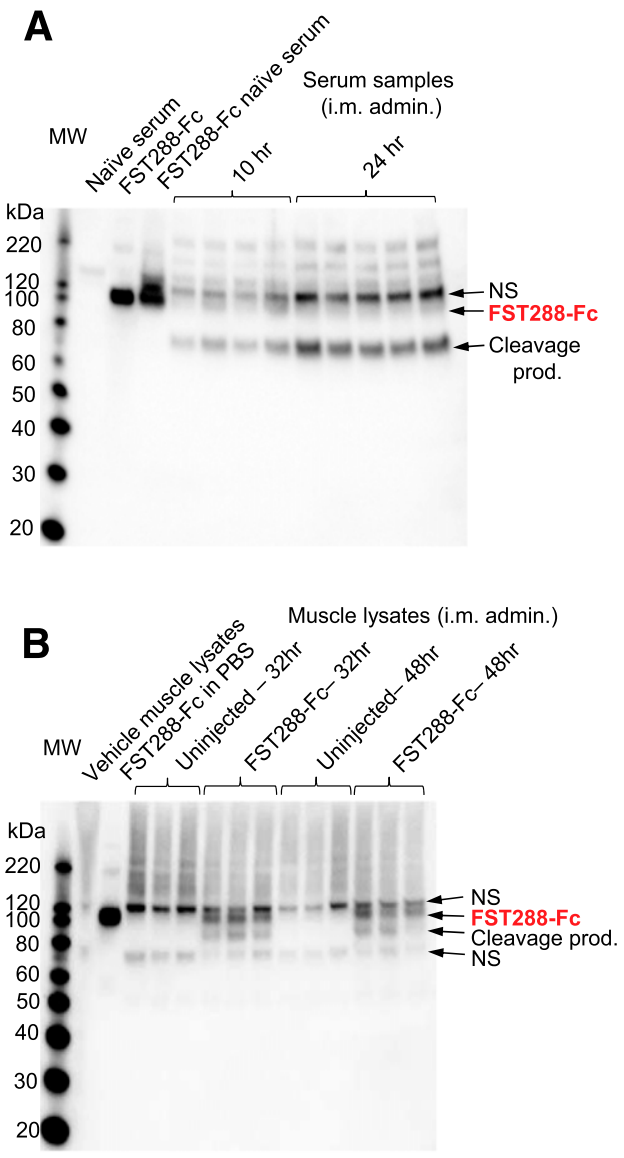
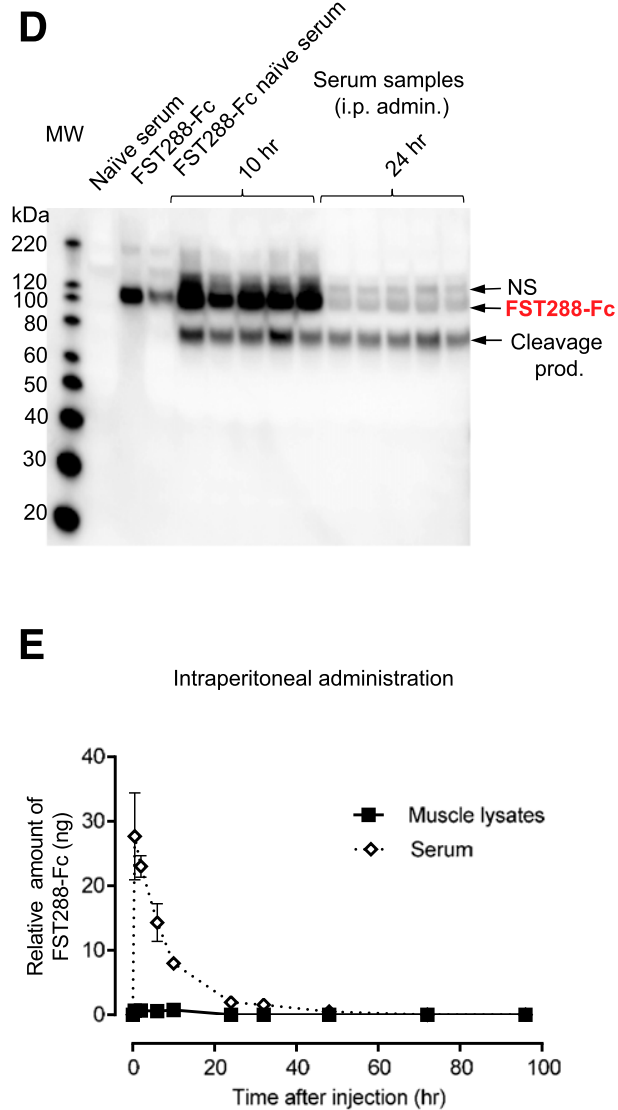

4. FST288-Fc in the circulation is rapidly cleaved. (A, B, and D) Serum and lysates of muscle collected from mice over a 96-hour time course were analyzed by nonreducing SDS-PAGE gels followed by Western blotting using an anti-follistatin antibody, with representative blots shown for intramuscular administration in (A) and (B) and for intraperitoneal administration in (D). Arrows indicate intact FST288-Fc, FST288-Fc cleavage products, and nonspecific bands observed in serum and muscle. Western blots were semiquantified by densitometry by comparison with an FST288-Fc internal control (5 ng) loaded on each gel. (C) Time course in mice of relative levels of intact FST288-Fc in serum and muscle lysates after intramuscular administration. (E) Time course in mice of relative levels of intact FST288-Fc in serum and muscle lysates after intraperitoneal administration. NS, nonspecific band; MW, molecular weight.
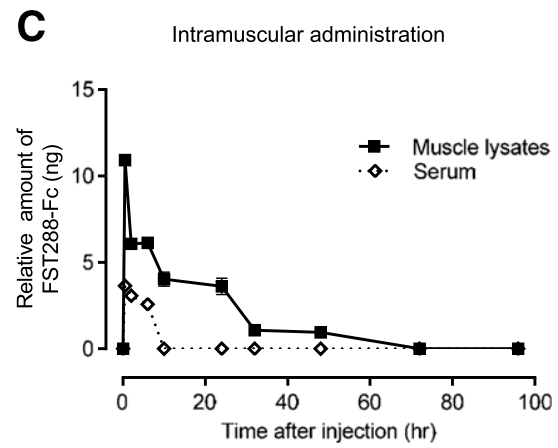

Combined use of $\mathrm{N}$-terminal sequencing and mass spectrometric analysis allowed us to identify two FST288-Fc fragments present in serum samples collected at 24 hours postadministration. Figure $6 \mathrm{~A}$ shows the amino acid sequence of FST288 with sites 1 and 2 indicating $\mathrm{N}$-terminal residues of these fragments, and Fig. $6 \mathrm{~B}$ indicates the location of these sites within the tertiary structure of FST288 (Protein Data Bank identifier 3HH2) (Cash et al., 2009). Since this characterization of cleavage products is based only on a single time point, additional analysis is required to determine whether FST288-Fc proteolysis was initiated at these sites or at residues closer to the $\mathrm{N}$ terminus. Simple cleavage of FST288-Fc at these sites near the FSD2-FSD3 boundary would detach the Fc domain from any ND-FSD1-FSD2 fragments and presumably render the latter susceptible to rapid elimination due to size.

\section{Discussion}

In this study, we provide the first characterization of musclerelated activity of a FST288-Fc fusion protein. FST288-Fc retains desirable properties of naturally occurring FST288 in vitro, potently neutralizing multiple TGF- $\beta$ superfamily ligands implicated as key inhibitors of skeletal muscle growth. Intramuscular administration of FST288-Fc in mice induced robust dose-dependent growth of the targeted muscle but not of surrounding or contralateral muscles, in contrast to the widespread muscle-hypertrophic effects of intramuscularly administered ActRIIB-Fc. Systemic administration of FST288-Fc in mice altered neither muscle mass nor body composition, in contrast to the pronounced activity of systemically administered ActRIIB-Fc. Finally, intact FST288-Fc was detectable in skeletal muscle tissue for at least 48 hours after intramuscular 


\section{A}

Serum taken from FST288-Fc treated mice

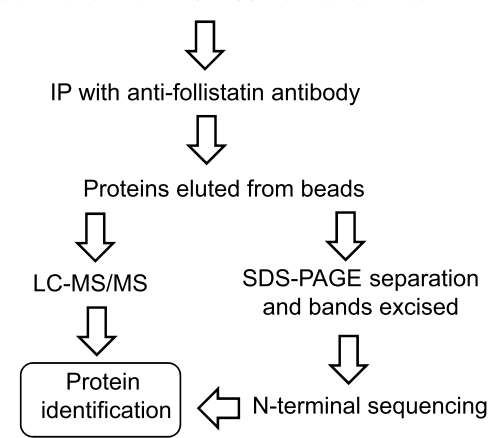

\section{B}

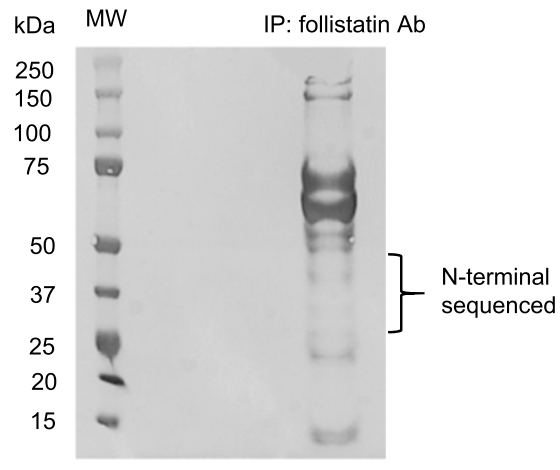

C

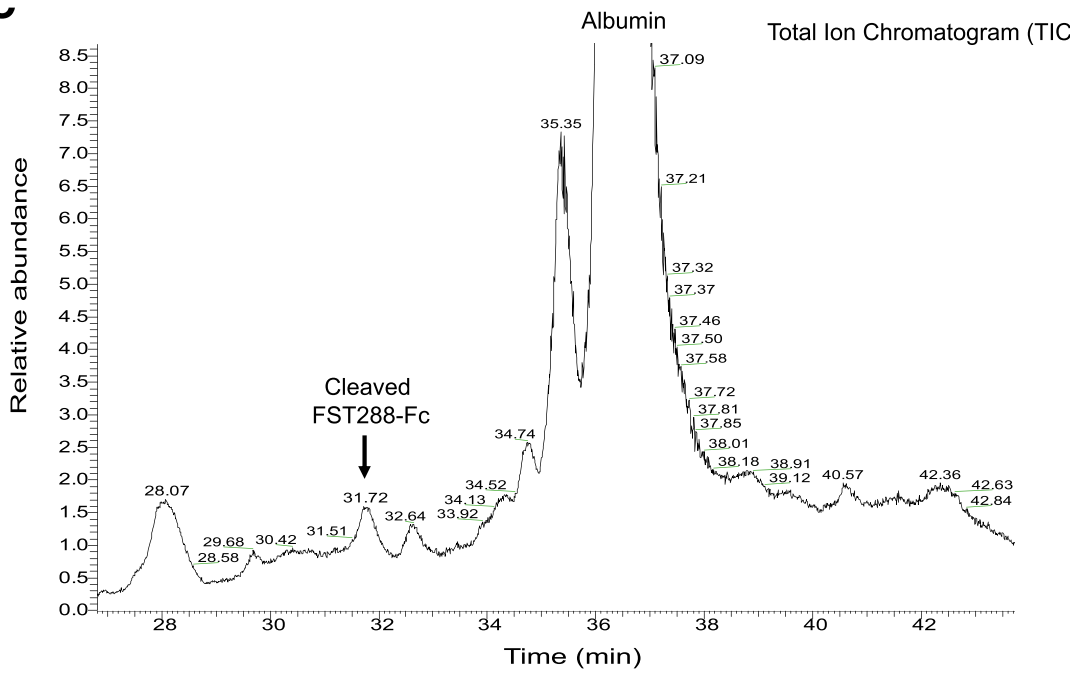

D

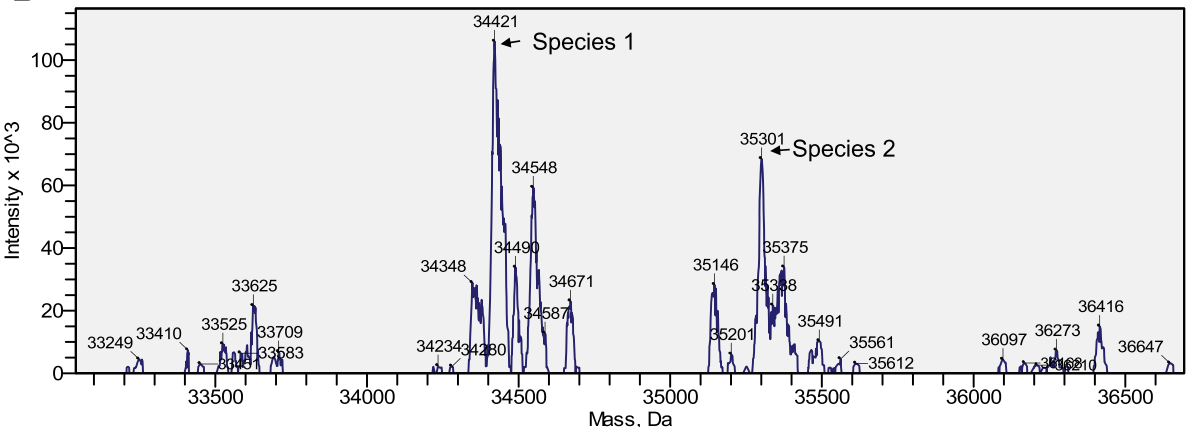

Fig. 5. Analysis of FST288-Fc cleavage products in the circulation of systemically treated mice. (A) Outline of analytic methods used to identify FST288-Fc cleavage products in the circulation. (B) Serum collected 24 hours after intraperitoneal administration of FST288-Fc was subjected to immunoprecipitation with an anti-follistatin antibody. Proteins obtained from this procedure were separated by reducing SDS-PAGE, and those in the range of $30-45 \mathrm{kDa}$ were characterized using $\mathrm{N}$-terminal sequencing. (C) Mass spectrometric analysis of the immunoprecipitated proteins revealed a small peak corresponding to follistatin sequences at 31.72 minutes as shown on the total ion chromatogram. (D) Deconvoluted mass spectrum from which two follistatin-derived proteins of 34,421 and 35,301 Da were identified. Ab, antibody; IP, immunoprecipitation; LC, liquid chromatography; MS/MS, tandem mass spectrometry; MW, molecular weight. administration, but circulating FST288-Fc underwent rapid proteolytic cleavage to form fragments with impaired ligand binding. These findings support further investigation of FST288-Fc and related agents to induce localized muscle growth under therapeutic circumstances in which selective hypertrophy is desirable.

The robust muscle growth observed here reflects the ability of follistatin to neutralize multiple endogenous inhibitors of muscle hypertrophy. Myostatin was the first secreted protein to be implicated in the homeostatic regulation of skeletal muscle mass (McPherron and Lee, 1997; Lee and McPherron, 1999). Subsequent studies have confirmed the importance of myostatin in many species, but also revealed that additional TGF- $\beta$ superfamily ligands (Lee, 2007), most notably activins
A and B, can act in combination with myostatin to further inhibit skeletal muscle hypertrophy (Gilson et al., 2009; Lee et al., 2010; Yaden et al., 2014; Latres et al., 2017), perhaps synergistically (Chen et al., 2017). Among these ligands, activins seem to play a more prominent role as muscle inhibitors in primates (Latres et al., 2017), whereas myostatin seems to be more prominent in rodents (Chen et al., 2017), which may partly explain why dedicated antimyostatin agents have generally performed better in preclinical than clinical studies (Wagner, 2008). The role of GDF11 in skeletal muscle homeostasis is less clear (Egerman et al., 2015; Harper et al., 2016; Walker et al., 2016), although its overexpression in mice leads to muscle atrophy (Hammers et al., 2017; Zimmers et al., 2017). Early investigation of muscle regulation by TGF- $\beta$ 
A

GNCWLRQAKNGRCQVLYKTELSKEECCS TGRLSTSWTEEDVNDNTLFKWMIFNGGA PNCIPCKETCENVDCGPGKKCRMNKKNK PRCVCAPDCSNITWKGPVCGLDGKTYRN ECALLKARCKEQPELEVQYQGRCKKTCR DVFCPGSSTCVVDQTNNAYCVTCNRICP EPASSEQYLCGNDGVTYSSACHLRKATC ${ }_{\text {LLGRS IGLA }}^{1} Y_{\text {EGKCIK }}^{2} A_{K S C E D I Q C T}$ GGKKCLWDFKVGRGRCSLCDELCPDSKS DEPVCASDNATYASECAMKEAACSSGVL LEVKHSGSCNT-FC

\section{B}

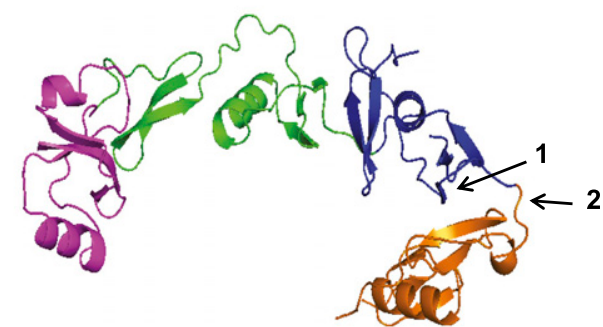

Fig. 6. Cleavage products of FST288-Fc identified in the circulation after its systemic administration in mice. (A) Amino acid sequence of the FST288 portion of FST288-Fc, indicating $\mathrm{N}$-terminal residues (numbered and enlarged letter codes) of the two cleavage products identified at 24 hours postadministration. (B) Three-dimensional structure of FST288 protein indicating positions of these two $\mathrm{N}$-terminal residues. Colors denote (left to right) N-terminal, FSD1, FSD2, and FSD3 domains.

superfamily ligands used mice with haploinsufficiency or overexpression of follistatin and thereby demonstrated its strong hypertrophic effects (Lee and McPherron, 2001; Lee, 2007; Gilson et al., 2009; Lee et al., 2010). In this study, locally administered FST288-Fc generated a muscle growth response comparable in magnitude to that of ActRIIB-Fc, which is consistent with their shared ability to inhibit myostatin, activins, and GDF11 with high affinity. Unlike ActRIIB-Fc, FST288-Fc does not bind BMP9, which differentiates it favorably from ActRIIB-Fc in terms of potential for unwanted vascular effects (Campbell et al., 2017).

Homeostatic regulation of skeletal muscle mass is now recognized to be dependent on a balance between opposing actions of the two main pathways of TGF- $\beta$ superfamily signaling. Myostatin, activins, and GDF11 are activators of Smad2/3 signaling, which opposes myofiber hypertrophy and promotes muscle catabolism. The other main group of superfamily ligands (BMPs and other GDFs) are generally activators of Smad1/5/8 signaling, which promote myofiber hypertrophy and protein synthesis (Sartori et al., 2013). Complex crosstalk between the Smad2/3 and Smad1/5/8 pathways at multiple levels contributes to their functional antagonism in muscle homeostasis (Sartori et al., 2013). Due to its preferential inhibition of Smad2/3 ligands, follistatin is thought to promote muscle hypertrophy and protein synthesis through increased apoptosis, reduced myoblast proliferation, and activation of mammalian target of rapamycin (Winbanks et al., 2012), as well as through indirect activation of BMPmediated Smad1/5/8 signaling.

Few studies of follistatin-based interventions for muscle disorders have used fusion proteins. Seeking a therapeutic agent to produce systemic muscle hypertrophy, Datta-Mannan et al. (2013) determined that intrinsic pharmacokinetic properties of the preferentially circulating follistatin isoform (FST315) are surprisingly unsuitable for a parenterally administered therapeutic with broad systemic effects. Removal or alteration of the native HBS in FST315 yields fusion proteins that produce widespread muscle growth in normal mice and mouse models of muscle injury after systemic administration (Datta-Mannan et al., 2013; Yaden et al., 2014; Shen et al., 2018). Here we have exploited properties of the preferentially pericellular follistatin isoform (FST288) as part of a fusion protein to induce focal muscle growth. Attachment of FST288 to an IgG Fc domain confers several advantages in this context. First, an Fc domain simplifies purification during protein production. Second, through its neonatal Fc receptor-binding motif, an Fc domain can promote recycling and delay lysosomal degradation of the fusion protein, thereby extending its half-life in the pericellular microenvironment (Rath et al., 2015). As an example, linkage of FST315 to an Fc domain extended its half-life in the circulation from 1.2 to 57 hours (Datta-Mannan et al., 2013). Finally, linkage to an Fc domain enables dimerization of FST288, which doubles the number of HBSs per molecule. HBSs can limit the spread of proteins like follistatin within tissues by slowing their diffusion (Rider and Mulloy, 2017) and can promote clearance and degradation of extracellular proteins, including follistatin-bound ligands (Hashimoto et al., 1997; Müller and Schier, 2011; Christianson and Belting, 2014; Matsuo and Kimura-Yoshida, 2014; Rider and Mulloy, 2017). The paired HBSs and rapid proteolytic cleavage in the circulation together promote pericellular localization of FST288 and focal action in targeted muscles.

Results from gene-transfer studies confirm the effectiveness of follistatin-based interventions for muscle growth and provide information regarding differential activity of follistatin isoforms. In a direct comparison of isoforms, acute overexpression of a native FST288 construct by electroporation increased gastrocnemius muscle mass in mice by nearly $40 \%$ compared with control vector, while native FST315 increased muscle mass by $24 \%$ (Yaden et al., 2014). Notably, similar overexpression of a FST288 variant lacking its heparinbinding site (FST288- $\Delta$ HBS) only increased muscle mass by $12 \%$, thus underscoring the importance of heparin-binding ability to the muscle-hypertrophic activity of FST288. In a separate study in mice, an intramuscular injection of recombinant adeno-associated viral vector expressing FST288 or FST315 produced comparably large increases in the mass of tibialis anterior muscle with either isoform, although intramuscular levels of FST288 were substantially higher than those of FST315 as expected (Winbanks et al., 2012). In addition, FST288 gene transfer was accompanied by a large increase in maximal force-producing capacity, providing evidence that follistatin-induced muscle mass is accompanied by increased strength. In another gene-transfer study in mice, local administration of viral vector expressing FST344 generated high serum levels of FST315, thereby increasing the mass of muscles distant from the site of administration (Haidet et al., 2008). Since circulating native follistatin 
(presumably FST315) is strongly implicated as a liverderived metabolic signal (Hansen and Plomgaard, 2016; Perakakis et al., 2018; Tao et al., 2018), its chronic augmentation with exogenous FST315 may be problematic. Together, these studies support FST288 as the preferred isoform to administer locally for induction of focal muscle growth in vivo.

Our results are at odds with a study in which recombinant FST288 reportedly remained intact in the circulation after systemic administration and was active in promoting muscle growth in mice (Gangopadhyay, 2013). Major differences between the two studies include the absence or presence of an Fc domain in the recombinant protein and the system used for protein expression (bacterial vs. mammalian), either of which could potentially have altered susceptibility of FST288 to proteolysis in the circulation. Although there was no evidence of such proteolysis in the earlier study, the time interval between FST288 administration and blood sampling for protein analysis was unreported. Consistent with our results, Yaden et al. (2014) found that FST288 derived from a mammalian expression system promoted muscle repair when administered intramuscularly but was inactive when administered systemically.

Follistatin can induce beneficial changes in skeletal muscle besides increased muscle mass and strength. Smad2/3 pathway activators such as myostatin not only increase protein catabolism but also stimulate muscle fibroblasts and fibrosis in models of skeletal muscle injury or disease (Li et al., 2008; Bo Li et al., 2012). Myostatin also promotes satellite cell quiescence, whereas inhibition of this pathway with follistatin or ActRIIB-Fc promotes muscle regeneration by activating satellite cells (McCroskery et al., 2003; Zhu et al., 2011; Formicola et al., 2018). Follistatin overexpression improves tissue repair after muscle injury, and follistatin-based interventions have shown signs of beneficial regenerative activity in preclinical models of muscular dystrophy or preliminary clinical studies (Rodino-Klapac et al., 2009; Yaden et al., 2014; Mendell et al., 2015, 2017). In addition, locally administered FST288-Fc facilitates muscle lengthening in an immobilization model of muscle-tendon unit deformity (Tinklenberg et al., 2018). Together, such results provide a compelling rationale for evaluating follistatin-based interventions like FST288-Fc in disorders with focal muscle weakness. A locally acting follistatin-Fc fusion protein, ACE-083, has been shown to promote focal muscle growth in a phase I study in healthy volunteers (Glasser et al., 2018) and is currently undergoing evaluation in a phase II study in patients with facioscapulohumeral muscular dystrophy and Charcot-Marie-Tooth disease.

\section{Acknowledgments}

We thank Asya Grinberg, Rita Steeves, and the Cell Culture Group at Acceleron Pharma for assistance with this project.

\section{Authorship Contributions}

Participated in research design: Castonguay, Lachey, Wallner, Strand, Davies, Sako, Mulivor, Pearsall, Kumar.

Conducted experiments: Wallner, Strand, Liharska, Watanabe, Cannell, Sako, Li.

Contributed new reagents or analytic tools: Davies.

Performed data analysis: Castonguay, Lachey, Wallner, Strand, Liharska, Sako, Troy, Krishnan, Li, Pearsall.

Wrote or contributed to the writing of the manuscript: Castonguay, Liharska, Sako, Troy, Krishnan, Li, Keates, Alexander, Pearsall, Kumar.

\section{References}

Amthor H, Nicholas G, McKinnell I, Kemp CF, Sharma M, Kambadur R, and Patel K (2004) Follistatin complexes myostatin and antagonises myostatin-mediated inhibition of myogenesis. Dev Biol 270:19-30.

Bilezikjian LM, Blount AL, Leal AM, Donaldson CJ, Fischer WH, and Vale WW (2004) Autocrine/paracrine regulation of pituitary function by activin, inhibin and follistatin. Mol Cell Endocrinol 225:29-36.

Bo Li Z, Zhang J, and Wagner KR (2012) Inhibition of myostatin reverses muscle fibrosis through apoptosis. $J$ Cell Sci 125:3957-3965.

Cadena SM, Tomkinson KN, Monnell TE, Spaits MS, Kumar R, Underwood KW, Pearsall RS, and Lachey JL (2010) Administration of a soluble activin type IIB receptor promotes skeletal muscle growth independent of fiber type. J Appl Physiol (1985) 109:635-642.

Campbell C, McMillan HJ, Mah JK, Tarnopolsky M, Selby K, McClure T, Wilson DM Sherman ML, Escolar D, and Attie KM (2017) Myostatin inhibitor ACE-031 treatment of ambulatory boys with Duchenne muscular dystrophy: results of a randomized, placebo-controlled clinical trial. Muscle Nerve 55:458-464.

Cash JN, Rejon CA, McPherron AC, Bernard DJ, and Thompson TB (2009) The structure of myostatin:follistatin 288: insights into receptor utilization and heparin binding. EMBO J 28:2662-2676

Chen JL, Walton KL, Hagg A, Colgan TD, Johnson K, Qian H, Gregorevic P, and Harrison CA (2017) Specific targeting of TGF- $\beta$ family ligands demonstrates distinct roles in the regulation of muscle mass in health and disease. Proc Nat Acad Sci USA 114:E5266-E5275.

Christianson HC and Belting M (2014) Heparan sulfate proteoglycan as a cell-surface endocytosis receptor. Matrix Biol 35:51-55.

Datta-Mannan A, Yaden B, Krishnan V, Jones BE, and Croy JE (2013) An engineered human follistatin variant: insights into the pharmacokinetic and pharmocodynamic relationships of a novel molecule with broad therapeutic potential. $J$ Pharmacol Exp Ther 344:616-623.

David L, Mallet C, Keramidas M, Lamandé N, Gasc JM, Dupuis-Girod S, Plauchu H, Feige JJ, and Bailly S (2008) Bone morphogenetic protein-9 is a circulating vascular quiescence factor. Circ Res 102:914-922.

David L, Mallet C, Mazerbourg S, Feige JJ, and Bailly S (2007) Identification of BMP9 and BMP10 as functional activators of the orphan activin receptor-like kinase 1 (ALK1) in endothelial cells. Blood 109:1953-1961.

Egerman MA, Cadena SM, Gilbert JA, Meyer A, Nelson HN, Swalley SE, Mallozzi C, Jacobi C, Jennings LL, Clay I, et al. (2015) GDF11 increases with age and inhibits skeletal muscle regeneration. Cell Metab 22:164-174.

Fainsod A, Deissler K, Yelin R, Marom K, Epstein M, Pillemer G, Steinbeisser H, and Blum M (1997) The dorsalizing and neural inducing gene follistatin is an antagonist of BMP-4. Mech Dev 63:39-50.

Formicola L, Pannérec A, Correra RM, Gayraud-Morel B, Ollitrault D, Besson V, Tajbakhsh S, Lachey J, Seehra JS, Marazzi G, et al. (2018) Inhibition of the activin receptor type-2B pathway restores regenerative capacity in satellite cell-depleted skeletal muscle. Front Physiol 9:515.

Gangopadhyay SS (2013) Systemic administration of follistatin288 increases muscle mass and reduces fat accumulation in mice. Sci Rep 3:2441.

Gilson H, Schakman O, Kalista S, Lause P, Tsuchida K, and Thissen JP (2009) Follistatin induces muscle hypertrophy through satellite cell proliferation and inhibition of both myostatin and activin. Am J Physiol Endocrinol Metab 297: E157-E164.

Glasser CE, Gartner MR, Wilson D, Miller B, Sherman ML, and Attie KM (2018) Locally acting ACE-083 increases muscle volume in healthy volunteers. Muscle Nerve 57:921-926.

Haidet AM, Rizo L, Handy C, Umapathi P, Eagle A, Shilling C, Boue D, Martin PT, Sahenk Z, Mendell JR, et al. (2008) Long-term enhancement of skeletal muscle mass and strength by single gene administration of myostatin inhibitors. Proc Natl Acad Sci USA 105:4318-4322.

Hammers DW, Merscham-Banda M, Hsiao JY, Engst S, Hartman JJ, and Sweeney HL (2017) Supraphysiological levels of GDF11 induce striated muscle atrophy. EMBO Mol Med 9:531-544.

Hansen JS and Plomgaard P (2016) Circulating follistatin in relation to energy metabolism. Mol Cell Endocrinol 433:87-93.

Harper SC, Brack A, MacDonnell S, Franti M, Olwin BB, Bailey BA, Rudnicki MA, and Houser SR (2016) Is growth differentiation factor 11 a realistic therapeutic for aging-dependent muscle defects? Circ Res 118:1143-1150, discussion 1150.

Hashimoto O, Nakamura T, Shoji H, Shimasaki S, Hayashi Y, and Sugino H (1997) A novel role of follistatin, an activin-binding protein, in the inhibition of activin action in rat pituitary cells. Endocytotic degradation of activin and its acceleration by follistatin associated with cell-surface heparan sulfate. J Biol Chem $\mathbf{2 7 2}$ 13835-13842.

Iemura S, Yamamoto TS, Takagi C, Uchiyama H, Natsume T, Shimasaki S, Sugino $\mathrm{H}$, and Ueno N (1998) Direct binding of follistatin to a complex of bone-morphogenetic protein and its receptor inhibits ventral and epidermal cell fates in early Xenopus embryo. Proc Natl Acad Sci USA 95:9337-9342.

Innis CA and Hyvönen M (2003) Crystal structures of the heparan sulfate-binding domain of follistatin. Insights into ligand binding. $J$ Biol Chem 278: 39969-39977.

Inouye S, Ling N, and Shimasaki S (1992) Localization of the heparin binding site of follistatin. Mol Cell Endocrinol 90:1-6.

Koncarevic A, Kajimura S, Cornwall-Brady M, Andreucci A, Pullen A, Sako D, Kumar R, Grinberg AV, Liharska K, Ucran JA, et al. (2012) A novel therapeutic approach to treating obesity through modulation of TGF $\beta$ signaling. Endocrinology 153:3133-3146.

Korchynskyi O and ten Dijke P (2002) Identification and functional characterization of distinct critically important bone morphogenetic protein-specific response elements in the Id1 promoter. J Biol Chem 277:4883-4891.

Kota J, Handy CR, Haidet AM, Montgomery CL, Eagle A, Rodino-Klapac LR, Tucker D, Shilling CJ, Therlfall WR, Walker CM, et al. (2009) Follistatin gene delivery 
enhances muscle growth and strength in nonhuman primates. Sci Transl Med 1: $6 \mathrm{ra} 15$.

Latres E, Mastaitis J, Fury W, Miloscio L, Trejos J, Pangilinan J, Okamoto H, Cavino $\mathrm{K}, \mathrm{Na} \mathrm{E}$, Papatheodorou A, et al. (2017) Activin A more prominently regulates muscle mass in primates than does GDF8. Nat Commun 8:15153.

Lee SJ (2007) Quadrupling muscle mass in mice by targeting TGF-beta signaling pathways. PLoS One 2:e789.

Lee SJ, Lee YS, Zimmers TA, Soleimani A, Matzuk MM, Tsuchida K, Cohn RD, and Barton ER (2010) Regulation of muscle mass by follistatin and activins. Mol Endocrinol 24:1998-2008.

Lee SJ and McPherron AC (1999) Myostatin and the control of skeletal muscle mass. Curr Opin Genet Dev 9:604-607.

Lee SJ and McPherron AC (2001) Regulation of myostatin activity and muscle growth. Proc Natl Acad Sci USA 98:9306-9311.

Lerch TF, Shimasaki S, Woodruff TK, and Jardetzky TS (2007) Structural and biophysical coupling of heparin and activin binding to follistatin isoform functions. $J$ Biol Chem 282:15930-15939.

Li ZB, Kollias HD, and Wagner KR (2008) Myostatin directly regulates skeletal muscle fibrosis. J Biol Chem 283:19371-19378.

Matsuo I and Kimura-Yoshida C (2014) Extracellular distribution of diffusible growth factors controlled by heparan sulfate proteoglycans during mammalian embryogenesis. Philos Trans R Soc Lond B Biol Sci 369:20130545.

McCorquodale D, Pucillo EM, and Johnson NE (2016) Management of CharcotMarie-Tooth disease: improving long-term care with a multidisciplinary approach. $J$ Multidiscip Healthc 9:7-19.

McCroskery S, Thomas M, Maxwell L, Sharma M, and Kambadur R (2003) Myostatin negatively regulates satellite cell activation and self-renewal. J Cell Biol 162:1135-1147.

McPherron AC, Lawler AM, and Lee SJ (1997) Regulation of skeletal muscle mass in mice by a new TGF- $\beta$ superfamily member. Nature 387:83-90.

Mendell JR, Sahenk Z, Al-Zaidy S, Rodino-Klapac LR, Lowes LP, Alfano LN, Berry K, Miller N, Yalvac M, Dvorchik I, et al. (2017) Follistatin gene therapy for sporadic inclusion body myositis improves functional outcomes. Mol Ther 25:870-879.

Mendell JR, Sahenk Z, Malik V, Gomez AM, Flanigan KM, Lowes LP, Alfano LN, Berry K, Meadows E, Lewis S, et al. (2015) A phase 1/2a follistatin gene therapy trial for Becker muscular dystrophy. Mol Ther 23:192-201.

Müller P and Schier AF (2011) Extracellular movement of signaling molecules. Dev Cell 21:145-158.

Nakamura T, Sugino K, Titani K, and Sugino H (1991) Follistatin, an activin-binding protein, associates with heparan sulfate chains of proteoglycans on follicular granulosa cells. J Biol Chem 266:19432-19437.

Nakamura T, Takio K, Eto Y, Shibai H, Titani K, and Sugino H (1990) Activinbinding protein from rat ovary is follistatin. Science 247:836-838.

Perakakis N, Upadhyay J, Ghaly W, Chen J, Chrysafi P, Anastasilakis AD, and Mantzoros CS (2018) Regulation of the activins-follistatins-inhibins axis by energy status: impact on reproductive function. Metabolism 85:240-249.

Rath T, Baker K, Dumont JA, Peters RT, Jiang H, Qiao SW, Lencer WI, Pierce GF, and Blumberg RS (2015) Fc-fusion proteins and FcRn: structural insights for longer-lasting and more effective therapeutics. Crit Rev Biotechnol 35:235-254.

Rider CC and Mulloy B (2017) Heparin, heparan sulphate and the TGF- $\beta$ cytokine superfamily. Molecules 22:713.

Rodino-Klapac LR, Haidet AM, Kota J, Handy C, Kaspar BK, and Mendell JR (2009) Inhibition of myostatin with emphasis on follistatin as a therapy for muscle disease. Muscle Nerve 39:283-296.

Sartori R, Schirwis E, Blaauw B, Bortolanza S, Zhao J, Enzo E, Stantzou A, Mouisel E, Toniolo L, Ferry A, et al. (2013) BMP signaling controls muscle mass. Nat Genet 45:1309-1318.

Schmierer B and Hill CS (2007) TGFbeta-SMAD signal transduction: molecular specificity and functional flexibility. Nat Rev Mol Cell Biol 8:970-982.

Schneyer A, Schoen A, Quigg A, and Sidis Y (2003) Differential binding and neutralization of activins A and B by follistatin and follistatin like-3 (FSTL-3/FSRP/ FLRG). Endocrinology 144:1671-1674.

Schneyer AL, Wang Q, Sidis Y, and Sluss PM (2004) Differential distribution of follistatin isoforms: application of a new FS315-specific immunoassay. J Clin Endocrinol Metab 89:5067-5075.

Schneyer AL, Sidis Y, Gulati A, Sun JL, Keutmann H, and Krasney PA (2008) Differential antagonism of activin, myostatin and growth and differentiation factor 11 by wild-type and mutant follistatin. Endocrinology 149:4589-4595.

Shen C, Iskenderian A, Lundberg D, He T, Palmieri K, Crooker R, Deng Q, Traylor $\mathrm{M}, \mathrm{Gu} \mathrm{S}$, Rong $\mathrm{H}$, et al. (2018) Protein engineering on human recombinan follistatin: enhancing pharmacokinetic characteristics for therapeutic application. J Pharmacol Exp Ther 366:291-302.

Shimasaki S, Koga M, Esch F, Cooksey K, Mercado M, Koba A, Ueno N, Ying SY Ling N, and Guillemin R (1988) Primary structure of the human follistatin precursor and its genomic organization. Proc Natl Acad Sci USA 85:4218-4222.

Sidis Y, Mukherjee A, Keutmann H, Delbaere A, Sadatsuki M, and Schneyer A (2006) Biological activity of follistatin isoforms and follistatin-like-3 is dependent on differential cell surface binding and specificity for activin, myostatin, and bone morphogenetic proteins. Endocrinology 147:3586-3597.

Sidis Y, Schneyer AL, and Keutmann HT (2005) Heparin and activin-binding determinants in follistatin and FSTL3. Endocrinology 146:130-136.

Stübgen JP and Stipp A (2010) Facioscapulohumeral muscular dystrophy: a prospective study of weakness and functional impairment. J Neurol 257:1457-1464 Sugino K, Kurosawa N, Nakamura T, Takio K, Shimasaki S, Ling N, Titani K, and Sugino H (1993) Molecular heterogeneity of follistatin, an activin-binding protein. Higher affinity of the carboxyl-terminal truncated forms for heparan sulfate proteoglycans on the ovarian granulosa cell. J Biol Chem 268:15579-15587.

Sumitomo S, Inouye S, Liu XJ, Ling N, and Shimasaki S (1995) The heparin binding site of follistatin is involved in its interaction with activin. Biochem Biophys Res Commun 208:1-9.

Tao R, Wang C, Stöhr O, Qiu W, Hu Y, Miao J, Dong XC, Leng S, Stefater M, Stylopoulos N, et al. (2018) Inactivating hepatic follistatin alleviates hyperglycemia. Nat Med 24:1058-1069.

Terry EE, Zhang X, Hoffmann C, Hughes LD, Lewis SA, Li J, Wallace MJ, Riley LA Douglas CM, Gutierrez-Monreal MA, et al. (2018) Transcriptional profiling reveals extraordinary diversity among skeletal muscle tissues. eLife 7:e34613.

Thompson TB, Lerch TF, Cook RW, Woodruff TK, and Jardetzky TS (2005) The structure of the follistatin:activin complex reveals antagonism of both type I and type II receptor binding. Dev Cell 9:535-543.

Tinklenberg J, Beatka M, Bain JLW, Siebers EM, Meng H, Pearsall RS, Lawlor MW, and Riley DA (2018) Use of ankle immobilization in evaluating treatments to promote longitudinal muscle growth in mice. Muscle Nerve 58:718-725.

Wagner KR (2008) Approaching a new age in Duchenne muscular dystrophy treatment. Neurotherapeutics 5:583-591.

Walker RG, Czepnik M, Goebel EJ, McCoy JC, Vujic A, Cho M, Oh J, Aykul S, Walton KL, Schang G, et al. (2017) Structural basis for potency differences between GDF8 and GDF11. BMC Biol 15:19.

Walker RG, Poggioli T, Katsimpardi L, Buchanan SM, Oh J, Wattrus S, Heidecker B, Fong YW, Rubin LL, Ganz P, et al. (2016) Biochemistry and biology of GDF11 and myostatin: similarities, differences, and questions for future investigation. Circ Res 118:1125-1141, discussion 1142 .

Winbanks CE, Weeks KL, Thomson RE, Sepulveda PV, Beyer C, Qian H, Chen JL, Allen JM, Lancaster GI, Febbraio MA, et al. (2012) Follistatin-mediated skeletal muscle hypertrophy is regulated by Smad3 and mTOR independently of myostatin. J Cell Biol 197:997-1008.

Yaden BC, Croy JE, Wang Y, Wilson JM, Datta-Mannan A, Shetler P, Milner A Bryant HU, Andrews J, Dai G, et al. (2014) Follistatin: a novel therapeutic for the improvement of muscle regeneration. J Pharmacol Exp Ther 349:355-371.

Zhang F, Beaudet JM, Luedeke DM, Walker RG, Thompson TB, and Linhardt RJ (2012) Analysis of the interaction between heparin and follistatin and heparin and follistatin-ligand complexes using surface plasmon resonance. Biochemistry $\mathbf{5 1}$ 6797-6803.

Zheng H, Qiao C, Tang R, Li J, Bulaklak K, Huang Z, Zhao C, Dai Y, Li J, and Xiao X (2017) Follistatin $\mathrm{N}$ terminus differentially regulates muscle size and fat in vivo. Exp Mol Med 49:e377.

Zhu J, Li Y, Lu A, Gharaibeh B, Ma J, Kobayashi T, Quintero AJ, and Huard J (2011) Follistatin improves skeletal muscle healing after injury and disease through an interaction with muscle regeneration, angiogenesis, and fibrosis. Am J Pathol 179: 915-930.

Zimmers TA, Jiang Y, Wang M, Liang TW, Rupert JE, Au ED, Marino FE, Couch ME, and Koniaris LG (2017) Exogenous GDF11 induces cardiac and skeletal muscle dysfunction and wasting [published correction appears in Basic Res Cardiol (2017) 112:53]. Basic Res Cardiol 112:48.

Address correspondence to: Dr. Roselyne Castonguay, Acceleron Pharma Inc., 128 Sidney St., Cambridge, MA 02139. E-mail: rcastonguay@acceleronpharma.com 